\title{
Admission Resting Heart Rate as an Independent Predictor of All-Cause Mortality in Elderly Patients with Hip Fracture
}

\author{
Zhicong Wang* \\ Xi Chen* \\ Yuxuan $\mathrm{Wu}^{*}$ \\ Wei Jiang \\ Ling Yang \\ Hong Wang \\ Shuping Liu \\ Yuehong Liu
}

Orthopaedic Center of Deyang City, Department of Orthopedics, Deyang People's Hospital, Deyang, Sichuan,

People's Republic of China

*These authors contributed equally to this work
Correspondence: Shuping Liu;

Yuehong Liu

Orthopaedic Center of Deyang City,

Department of Orthopedics, Deyang

People's Hospital, No. 173 Taishan North

Road, Jingyang District, Deyang, 618000,

People's Republic of China

Tel +868382418102

Fax +868382418102

Email doctorliushuping@।26.com;

doctorliuyuehong@I63.com
Purpose: To investigate the relationship between admission resting heart rate (RHR) and all-cause mortality in elderly patients with hip fracture.

Methods: A retrospective cohort study with 837 patients based on the established hip fracture database was conducted. Admission RHR was measured via electrocardiogram, and patients were grouped by the median RHR value (beats per minute, bpm). The main outcomes were 1-year and total all-cause mortality. Cox proportional hazard models and restricted cubic spline were used to assess the relationship between RHR and mortality. Sensitivity analyses were further performed to determine whether the results were stable.

Results: The mean and median RHR were 82.3 and 80.0 bpm, respectively. After a median follow-up of 31.8 months, the 1-year and total all-cause mortality were $17.6 \%$ and $31.2 \%$. Multivariable Cox analyses showed that high RHR was an independent risk factor for 1-year mortality $(H R=1.51 ; 95 \% C I: 1.08-2.13 ; p=0.016)$, and total mortality $(H R=1.44 ; 95 \%$ CI: $1.12-1.85 ; p=0.005)$. For each $10 \mathrm{bpm}$ increase in RHR, the risk of 1-year death increased by $23.0 \%(H R=1.23 ; 95 \% C I: 1.09-1.39 ; p=0.001)$, and total death increased by $21.0 \%(H R=1.21 ; 95 \% C I: 1.09-1.34 ; p<0.001)$. A typical J-shaped curve was observed in the restricted cubic spline for the association between RHR and 1-year mortality, with the lowest mortality risk at $70 \mathrm{bpm}$. Sensitivity analyses yielded similar findings.

Conclusion: An increase in RHR was independently associated with all-cause mortality, and may be a useful prognostic predictor for elderly patients with hip fracture.

Keywords: elderly, hip fracture, resting heart rate, prognosis, mortality

\section{Introduction}

Resting heart rate (RHR) is an easily accessible physiological indicator which reflects the activity of the autonomic nervous system. Regarding its predictive value, elevated RHR was found to be associated with a higher risk of all-cause mortality in various cardiovascular diseases (CVD), such as hypertension, ${ }^{1}$ heart failure, ${ }^{2}$ myocardial infarction ${ }^{3}$ and chronic aortic regurgitation. ${ }^{4}$ Recently, this association has also been observed in patients with chronic obstructive pulmonary disease (COPD), ${ }^{5}$ diabetes, ${ }^{6}$ and even in the general population. ${ }^{7}$ Notably, Li et $\mathrm{al}^{8}$ found that high RHR was an important risk factor for both all-cause mortality and CVD events in older subjects but not in younger people.

Hip fracture is a common fracture in elderly patients, and frequently comorbid with the aforementioned diseases. ${ }^{9}$ Therefore, we hypothesized that an increase in RHR may have an important impact on prognosis in elderly patients with hip 
fracture. However, only one previous study has reported that older women with rapid RHR had an increased risk of mortality in hip fracture patients. ${ }^{10}$ In the present study, by utilizing the established hip fracture database, ${ }^{11}$ we were able to investigate the relationship between admission RHR and all-cause mortality.

\section{Methods}

\section{Study Design and Patients}

This was a retrospective cohort design. As we previously described, ${ }^{11}$ hip fracture patients admitted to the Orthopaedic Center of Deyang City from January 2014 to December 2020 were enrolled consecutively. Briefly, the inclusion criteria for this database were as follows: (1) diagnosis of hip fracture; (2) age $\geq 60$ years; (3) fresh fracture less than 3 weeks. Any pathological fractures or fractures resulting from a high energy trauma were excluded from the database. In the current study, patients with atrial fibrillation or missing mortality data were then excluded. The study was performed according to the Declaration of Helsinki, and approved by the Institutional Ethics Committee of Deyang People's Hospital. As a retrospective study, the Ethics Committee agreed to waive the requirement for the informed consent, and all patient-related data were anonymized to ensure confidentiality.

\section{Data Collection and Definition}

The following characteristics were extracted from the clinical database: age at admission (years), sex (male or female), height $(\mathrm{m})$ and weight $(\mathrm{kg})$, current smoking and drinking status (yes or no), hip fracture type (femur neck fracture or intertrochanteric fracture), hypertension (yes or no) and treatment modality (surgical and nonsurgical). Patient comorbidity was assessed with the Charlson comorbidity index (CCI), which is one of the most widely used comorbidity models. ${ }^{12}$ Moreover, admission laboratory data related to the prognosis of hip fracture patients were also obtained, including lymphocyte [reference range: $\left.(1.1-3.2) \times 10^{9} / \mathrm{L}\right]$, hemoglobin (reference range: $130.0-175.0 \mathrm{~g} / \mathrm{L}$ ), and albumin (reference range: $35.0-55.0 \mathrm{~g} / \mathrm{L})$.

For a better understanding of the results, age was grouped into four categories: 60-69 years, 70-79 years, 80-89 years and $\geq 90$ years. Body mass index (BMI) was calculated as weight $(\mathrm{kg}) /[\text { height }(\mathrm{m})]^{2}$, and grouped as follows: underweight (BMI $《 18.5 \mathrm{~kg} / \mathrm{m}^{2}$ ), normal weight
$\left(\mathrm{BMI}=18.5-24.9 \mathrm{~kg} / \mathrm{m}^{2}\right)$, and overweight $(\mathrm{BMI} \geq$ $\left.25.0 \mathrm{~kg} / \mathrm{m}^{2}\right)$. The CCI score was calculated based on 17 diseases, and categorized as none $(\mathrm{CCI}=0)$, low $(\mathrm{CCI}=1)$ and high $(\mathrm{CCI} \geq 2) .{ }^{12}$ Hypertension was defined as systolic blood pressure $\geq 140 \mathrm{mmHg}$ or diastolic blood pressure $\geq$ $90 \mathrm{mmHg}$ or taking any antihypertensive drugs. According to the lower limit of reference range, lymphopenia and hypoalbuminemia were defined as an absolute lymphocyte count $<1.1 \times 10^{9} / \mathrm{L}$ and serum albumin $<35.0 \mathrm{~g} / \mathrm{L}$, respectively. Based on the World Health Organization (WHO) criteria, anemia was defined as hemoglobin level $<130 \mathrm{~g} /$ $\mathrm{L}$ for men and $<120 \mathrm{~g} / \mathrm{L}$ for women.

\section{RHR Measurement}

On admission, all patients routinely underwent a 12-lead electrocardiography (aECG-18U; Nalong Technologies, China) after 5 minutes of bed rest. RHR (beats per minute, bpm) was measured by assessing the time between each R wave on the ECG record. According to the median value, patients were divided into 2 groups: low RHR group and high RHR group.

\section{Follow-Up and Outcome}

All surviving patients in the database were telephonically followed up after hospital discharge, and the follow-up contents included survival status (alive or dead) and the date of death. For patients who died in hospital, the date of death was obtained from medical record. Survival time was defined as the time interval from the date of hospital admission to the date of death from any cause or the last follow-up date (December 31, 2020), whichever occurred first. In this study, the main outcomes were 1-year allcause mortality and total all-cause mortality at the last follow-up.

\section{Statistical Analysis}

Prior to analysis, missing values were checked and imputed using a multivariate normal imputation method. ${ }^{13}$ Continuous data were assessed for normality using the Shapiro-Wilk test. Normally distributed variables were described as means \pm standard deviation (SD), and analyzed by independent Student's $t$-test, while non-normally distributed variables were expressed as median (Q1, Q3), and performed using Wilcoxon rank-sum test. Categorical data were presented as frequencies (percentages), and compared by chi-square test. Survival probability among the RHR groups was estimated by the Kaplan-Meier and Log rank test, and the median follow- 
up time was calculated by the reverse Kaplan-Meier method. Univariable Cox proportional hazard models were used to identify potential predictor variables, and factors with $p<0.10$ were then entered into the multivariable Cox analyses to investigate the association between RHR and mortality. Model 1 was adjusted for age, sex and BMI. Model 2 was additionally adjusted for hip fracture type, CCI, treatment modality, lymphopenia, anemia and hypoalbuminemia. In addition, Cox models with the same covariates were also performed with RHR as a continuous variable (10 bpm increase). To better investigate the potential non-linear association between RHR and 1-year mortality, adjusted Cox model using restricted cubic spline with 5 knots was further constructed. Considering that RHR may be influenced by the use of antihypertensive drugs, sensitivity analyses were further performed to determine whether the results persisted in patients with or without hypertension. A twotailed $p<0.05$ was considered statistically significant. All the statistical analyses were performed with JMP Pro software (version 13.0.0; SAS Institute Inc., Cary, $\mathrm{NC}, \mathrm{USA})$.

\section{Results}

\section{Baseline Characteristics}

Out of 1044 patients in the original database, 207 patients were excluded according to the exclusion criteria. Ultimately, a total of 837 patients were included in the final analysis (Figure 1). The patient characteristics are listed in Table 1. Overall, the mean age was $78.8 \pm 8.6$ years, 552 (65.9\%) were female, and the mean and median RHR were 82.3 and $80.0 \mathrm{bpm}$, respectively. Among these patients, $423(50.5 \%)$ had below median RHR ( $\leq 80 \mathrm{bpm})$, and 414 (49.5\%) had above median RHR (>80 bpm). Patients with a higher RHR were more likely to receive non-surgical treatment $(32.1 \%$ vs $23.2 \%, p=0.004)$, while no significant differences were found with regard to demographics and laboratory data.

\section{RHR and All-Cause Mortality}

After a median follow-up of 31.8 months, 147 (17.6\%) and $261(31.2 \%)$ patients died within 1 year and the last followup. Compared with low RHR group, high RHR group suffered a higher 1 -year mortality $(22.3 \%$ vs $13.1 \%, p=0.001)$ and total mortality $(36.0 \%$ vs $26.5 \%, p=0.003)$. Also, Kaplan-Meier analysis showed that high RHR patients had significantly worse survival than low RHR patients (log rank

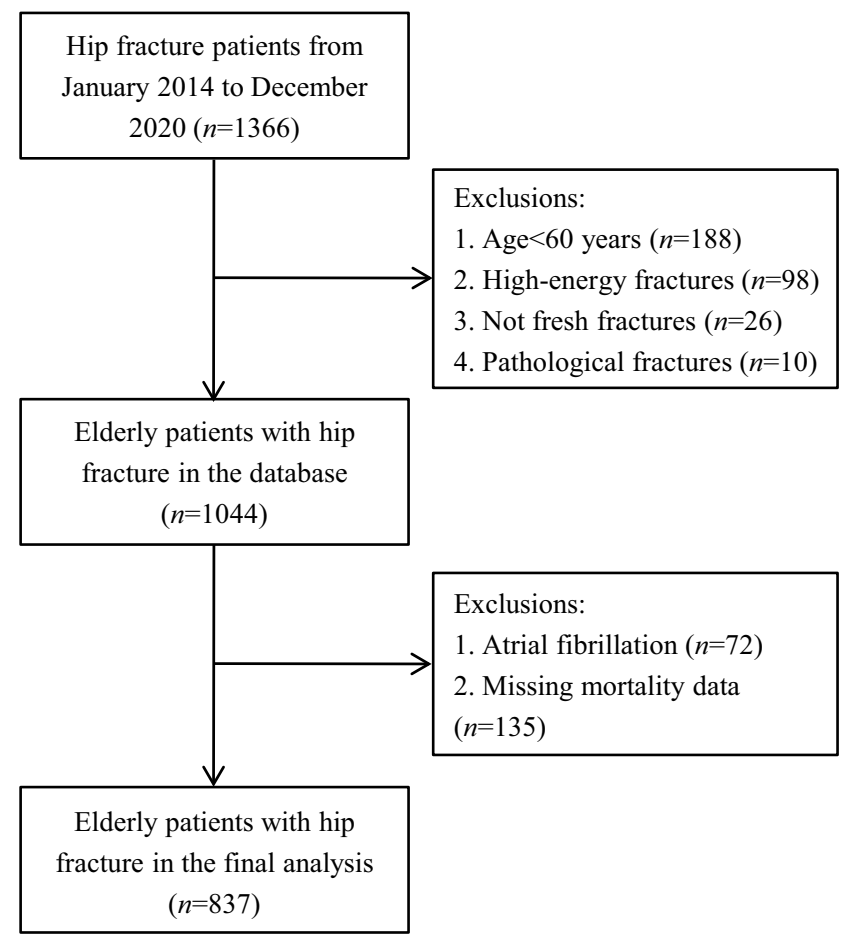

Figure I Flow chart of the study.

$\chi^{2}=11.67, p=0.001$; Figure 2). Consistent with the results, each $10 \mathrm{bpm}$ increase in RHR was associated with a higher risk of 1-year and total mortality, with unadjusted hazard ratios $(H R)$ of $1.44(95 \% C I: 1.26-1.63)$ and $1.30(95 \% C I$ : 1.18-1.44), respectively (Table 2). In addition, age, sex, BMI, hip fracture type, CCI score, treatment modality, lymphopenia, anemia and hypoalbuminemia were influencing factors for both 1-year and total mortality (all $p<0.05$ ).

After further adjusting for the above potential confounding variables (model 2, Table 3), high RHR remained an independent risk factor for 1-year mortality $(H R=1.51$; 95\% CI: $1.08-$ $2.13 ; p=0.016)$, and total mortality $(H R=1.44 ; 95 \% C I$ : $1.12-1.85 ; p=0.005)$. For each $10 \mathrm{bpm}$ increase in RHR, the risk of 1-year death increased by $23.0 \%(H R=1.23 ; 95 \% C I$ : $1.09-1.39 ; p=0.001)$, and total death at the last follow-up increased by $21.0 \%(H R=1.21 ; 95 \% C I: 1.09-1.34 ; p<$ 0.001). To further explore non-linear relationship, a typical J-shaped curve was observed in the restricted cubic spline for the association between RHR and 1-year mortality, with the lowest mortality risk at $70 \mathrm{bpm}$ (Figure 3).

\section{Sensitivity Analysis}

To further identify whether hypertension might influence the relationship between RHR and mortality, sensitivity analyses were conducted (Table 4). The results were 
Table I Patient Characteristics According to Admission Resting Heart Rate

\begin{tabular}{|c|c|c|c|c|}
\hline Characteristics & Total $(n=837)$ & $\begin{array}{c}\text { Low } R H R \leq 80 \mathrm{bpm} \\
(n=423)\end{array}$ & $\begin{array}{c}\text { High RHR > } 80 \mathrm{bpm} \\
(n=4 \mid 4)\end{array}$ & $p$ value \\
\hline Age (years) & $78.8 \pm 8.6$ & $78.5 \pm 8.2$ & $79.2 \pm 9.0$ & $0.28 \mathrm{I}$ \\
\hline 60-69 years, n (\%) & $145(17.3)$ & $74(17.5)$ & $71(17.1)$ & 0.229 \\
\hline 70-79 years, n (\%) & $264(31.5)$ & $137(32.4)$ & $127(30.7)$ & \\
\hline 80-89 years, n (\%) & $345(4 I .2)$ & $179(42.3)$ & $166(40.10)$ & \\
\hline$\geq 90$ years, $\mathrm{n}(\%)$ & $83(9.9)$ & $33(7.8)$ & $50(12.1)$ & \\
\hline Female, n (\%) & $552(65.9)$ & $273(64.5)$ & $279(67.4)$ & 0.384 \\
\hline BMI $\left(\mathrm{kg} / \mathrm{m}^{2}\right)$ & $21.64 \pm 2.7$ & $21.67 \pm 2.6$ & $21.61 \pm 2.8$ & 0.732 \\
\hline Underweight, n (\%) & $79(9.4)$ & $38(9.0)$ & $4 \mid(9.9)$ & 0.876 \\
\hline Normal weight, n (\%) & $689(82.3)$ & $349(82.5)$ & $340(82.1)$ & \\
\hline Overweight, n (\%) & $69(8.2)$ & $36(8.5)$ & $33(8.0)$ & \\
\hline Current smoker, n (\%) & $137(16.4)$ & $75(17.7)$ & $62(15.0)$ & 0.282 \\
\hline Current drinker, n (\%) & $83(9.9)$ & $48(11.3)$ & $35(8.5)$ & 0.161 \\
\hline Admission RHR (bpm) & $82.3 \pm 12.3$ & $72.9 \pm 6.6$ & $91.9 \pm 8.9$ & $<0.001$ \\
\hline Hip fracture type, n (\%) & & & & 0.426 \\
\hline Femoral neck & $416(49.7)$ & $216(51.1)$ & $200(48.3)$ & \\
\hline Intertrochanteric & $421(50.3)$ & $207(48.9)$ & $214(51.7)$ & \\
\hline \multicolumn{4}{|l|}{$\mathrm{CCl}, \mathrm{n}(\%)$} & 0.695 \\
\hline None & $428(5 I .1)$ & $222(52.5)$ & $206(49.7)$ & \\
\hline Low & $247(29.5)$ & $123(29.1)$ & $124(30.0)$ & \\
\hline High & $162(19.4)$ & $78(18.4)$ & $84(20.3)$ & \\
\hline Hypertension, n (\%) & $290(34.6)$ & $153(36.2)$ & $137(33.1)$ & 0.349 \\
\hline Surgical treatment, n (\%) & $606(72.4)$ & $325(76.8)$ & $28 I(67.9)$ & 0.004 \\
\hline Lymphocyte $\left(\times 10^{9} / \mathrm{L}\right)$ & $0.96(0.67,1.25)$ & $0.95(0.68,1.24)$ & $0.97(0.67,1.25)$ & 0.985 \\
\hline Lymphopenia, n (\%) & $535(63.9)$ & $269(63.6)$ & $266(64.3)$ & 0.843 \\
\hline Hemoglobin $(g / L)$ & $110.3 \pm 20.9$ & $111.3 \pm 19.8$ & $109.3 \pm 21.9$ & 0.183 \\
\hline Anemia, n (\%) & $594(71.0)$ & $299(70.7)$ & $295(71.3)$ & 0.856 \\
\hline Albumin $(\mathrm{g} / \mathrm{dL})$ & $38.7 \pm 4.7$ & $38.9 \pm 4.5$ & $38.4 \pm 4.9$ & 0.151 \\
\hline Hypoalbuminemia, n (\%) & $176(2 \mid .0)$ & $88(20.8)$ & $88(21.3)$ & 0.873 \\
\hline
\end{tabular}

Abbreviations: RHR, resting heart rate; bpm, beats per minute; BMI, body mass index; $\mathrm{CCl}$, Charlson comorbidity index.

consistent with the main findings, and no significant hypertension $\times$ RHR interactions were observed.

\section{Discussion}

In this study, we consecutively included hip fracture patients from the established database, and found that admission RHR was significantly associated with 1-year mortality and total mortality at the last follow-up, even after controlling for potential confounding factors. Moreover, a typical J-shaped curve was observed in restricted cubic spline for the association between RHR and 1-year mortality, suggesting that RHR may be a useful prognostic predictor for elderly patients with hip fracture.
RHR is an important indicator of the health of the cardiovascular system, and easy to obtain clinically. Recently, increasing evidences have revealed that RHR may be a marker of healthy aging. ${ }^{14}$ Hartaigh et al ${ }^{15}$ analyzed 5691 older adults aged 65 years and over, and measured RHR annually for six consecutive years. The results showed that each $10 \mathrm{bpm}$ increase in RHR had $33 \%$ greater hazard of all-cause mortality, which was consistent with the study by Floyd et al. ${ }^{16}$ Another study also found a similar risk relationship in the elderly population, but not in young adults. ${ }^{8}$ As is well known, hip fractures occur commonly in the elderly, and frequently combined with cardiovascular diseases, such as heart failure, coronary artery disease and atrial 


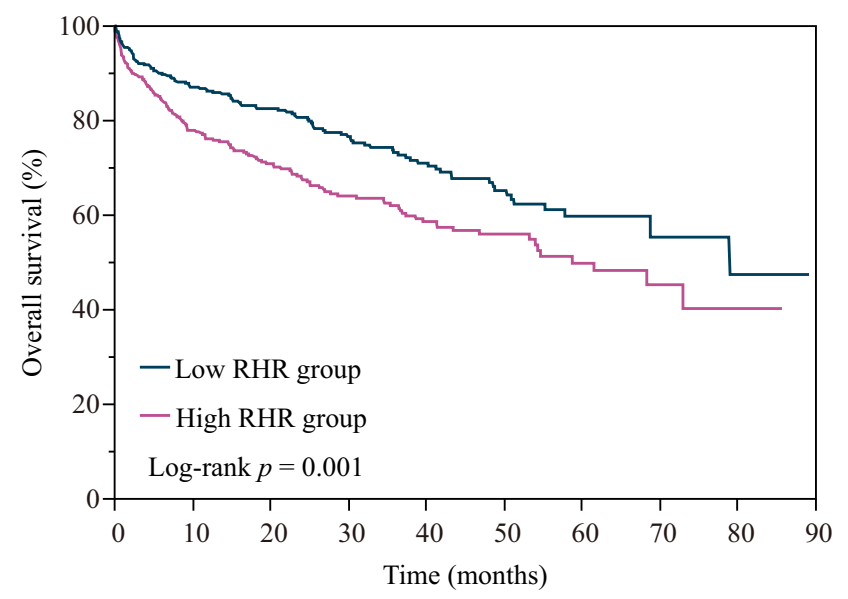

Figure 2 Kaplan-Meier survival analysis for overall survival according to high and low resting heart rate (RHR).

fibrillation, which have been identified as independent risk factors for hip fracture survival. ${ }^{9,17,18}$ However, to our knowledge, this is the first study to clearly demonstrate that an elevated RHR is associated with a higher all-cause mortality in elderly patients with hip fracture. Moreover, with each $10 \mathrm{bpm}$ increase in RHR, the risk of 1 -year death increased by $23.0 \%$, and total death at the last follow-up increased by $21.0 \%$.

Moreover, some studies utilized restricted cubic splines to explore the potential non-linear relationship between RHR and mortality. Cui et $\mathrm{al}^{19}$ found a U-shaped association between time-updated RHR and all-cause or cardiovascular mortality in a random middle-aged male cohort, and $60 \mathrm{bpm}$ was associated with the lowest mortality, suggesting that both high and low RHR correlated with increased mortality in the general population. Also, the U-shaped curve was seen in critically ill patients, providing a new insight for optimizing HR control strategies. ${ }^{20}$ Yet, other studies observed a $\mathrm{J}$-shaped association in acute ischemic stroke patients, ${ }^{21}$ myocardial infarction patients, ${ }^{22}$ and

Table 2 Univariable Cox Regression Analysis for the Risk Factors Associated with I-Year and Total All-Cause Mortality

\begin{tabular}{|c|c|c|c|c|}
\hline \multirow[t]{2}{*}{ Variables } & \multicolumn{2}{|c|}{ I-Year Mortality } & \multicolumn{2}{|c|}{ Total Mortality } \\
\hline & HR (95\% Cl) & $p$ value & HR $(95 \% \mathrm{Cl})$ & $p$ value \\
\hline \multicolumn{5}{|l|}{ Age (years) } \\
\hline $60-69$ & I.0 (reference) & - & I.0 (reference) & - \\
\hline $70-79$ & $3.25(1.56-7.93)$ & 0.001 & $2.60(1.53-4.70)$ & $<0.001$ \\
\hline $80-89$ & $4.83(2.39-11.54)$ & $<0.001$ & $3.89(2.35-6.92)$ & $<0.001$ \\
\hline$\geq 90$ & $6.58(2.99-16.53)$ & $<0.001$ & $6.46(3.68-11.99)$ & $<0.001$ \\
\hline Sex (male vs female) & $1.68(1.21-2.32)$ & 0.002 & $1.28(0.99-1.65)$ & 0.056 \\
\hline \multicolumn{5}{|l|}{ BMI } \\
\hline Underweight & $1.10(0.62-1.82)$ & 0.722 & $0.92(0.53-1.48)$ & 0.739 \\
\hline Normal weight & 1.0 (reference) & - & 1.0 (reference) & - \\
\hline Overweight & $0.39(0.14-0.86)$ & 0.017 & $0.49(0.22-0.93)$ & 0.027 \\
\hline Current smoker & $1.30(0.85-1.93)$ & 0.212 & $1.30(0.94-1.77)$ & 0.112 \\
\hline Current drinker & $1.07(0.60-1.76)$ & 0.815 & $1.08(0.70-1.59)$ & 0.728 \\
\hline Admission RHR (High vs Low) & $1.80(1.29-2.52)$ & 0.001 & $1.54(1.20-1.97)$ & 0.001 \\
\hline HR (Each 10 bpm increase) & $1.44(1.26-1.63)$ & $<0.001$ & $1.30(1.18-1.44)$ & $<0.001$ \\
\hline Hip fracture type (intertrochanteric vs neck) & $1.35(0.97-1.87)$ & 0.072 & $1.64(1.27-2.11)$ & $<0.001$ \\
\hline \multicolumn{5}{|l|}{$\mathrm{CCl}$} \\
\hline None & I.0 (reference) & - & I.0 (reference) & - \\
\hline Low & $1.96(1.29-2.95)$ & 0.002 & $1.83(1.36-2.46)$ & $<0.001$ \\
\hline High & $4.11(2.78-6.11)$ & $<0.001$ & $3.48(2.57-4.69)$ & $<0.001$ \\
\hline Surgical treatment (No vs Yes) & $8.36(5.90-12.05)$ & $<0.001$ & $4.82(3.76-6.18)$ & $<0.001$ \\
\hline Lymphopenia (Yes vs No) & $1.74(1.21-2.55)$ & 0.002 & $1.49(1.15-1.94)$ & 0.003 \\
\hline Anemia (Yes vs No) & $1.82(1.22-2.80)$ & 0.003 & $1.71(1.27-2.35)$ & $<0.001$ \\
\hline Hypoalbuminemia (Yes vs No) & $2.13(1.51-2.97)$ & $<0.001$ & $1.77(1.35-2.29)$ & $<0.001$ \\
\hline
\end{tabular}

Abbreviations: $\mathrm{HR}$, hazard ratio; $\mathrm{Cl}$, confidence interval; $\mathrm{BMI}$, body mass index; $\mathrm{RHR}$, resting heart rate; bpm, beats per minute; $\mathrm{CCl}$, Charlson comorbidity index. 
Table 3 Multivariable Cox Regression Analysis for Admission Resting Heart Rate Associated with I-Year and Total All-Cause Mortality

\begin{tabular}{|l|c|c|c|c|}
\hline \multirow{2}{*}{} & \multicolumn{2}{|c|}{ I-Year Mortality } & \multicolumn{2}{c|}{ Total Mortality } \\
\cline { 2 - 5 } & HR (95\% Cl) & P value & HR (95\% CI) & P value \\
\hline Admission RHR (High vs Low) & & & & \\
Model I & $1.79(1.28-2.5 I)$ & 0.001 & $1.56(1.22-2.00)$ & 0.001 \\
Model 2 & $1.51(1.08-2.13)$ & 0.016 & $1.44(1.12-1.85)$ & 0.005 \\
\hline Admission RHR (Each 10 bpm & & & & $<0.001$ \\
increase) & $1.43(1.26-1.62)$ & $<0.001$ & $1.32(1.19-1.46)$ & $<0.001$ \\
Model I & $1.23(1.09-1.39)$ & 0.001 & $1.21(1.09-1.34)$ & \\
Model 2 & & & \\
\hline
\end{tabular}

Notes: Model I adjusted for age, sex and body mass index. Model 2 adjusted for model I plus hip fracture type, Charlson comorbidity index, treatment modality, lymphopenia, anemia and hypoalbuminemia.

Abbreviations: $\mathrm{HR}$, hazard ratio; $\mathrm{Cl}$, confidence interval; $\mathrm{RHR}$, resting heart rate.

even in the general population. ${ }^{23}$ In agreement with the latter observations, we also observed a typical J-shaped curve for the association between RHR and 1-year mortality, and $70 \mathrm{bpm}$ exhibited the lowest mortality risk.

Indeed, RHR may be easily affected by the use of antihypertensive medications, such as beta-blocker treatment. Recently, a meta-analysis that included 189,385 patients revealed no association between betablockers use and all-cause mortality in acute myocardial infarction. ${ }^{24}$ Nevertheless, a beneficial effect of beta-blocker treatment has been previously reported in elderly patients with heart failure. ${ }^{25,26}$ In addition,

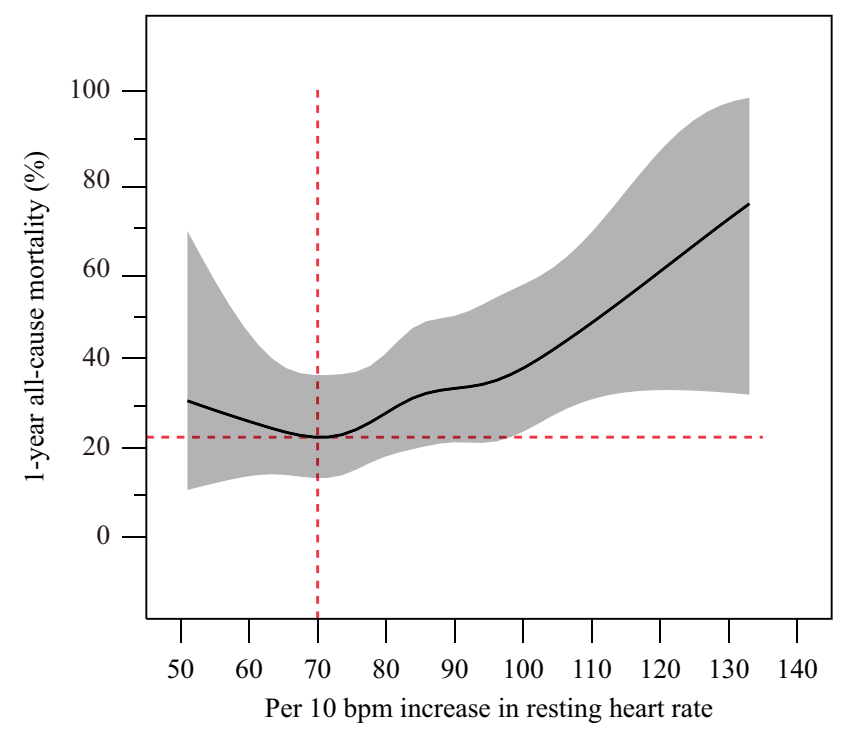

Figure 3 Restricted cubic spline for the association between resting heart rate (RHR) and I-year all-cause mortality.
2 large cohort studies with more than 120,000 hip fracture patients also found that beta-blocker therapy was independently associated with a reduction in mortality. ${ }^{27,28}$ Due to the lack of detailed and reliable medication history, we were unable to conduct an analysis among patients with or without beta-blocker treatment. However, we attempted to address this limitation with sensitivity analysis in patients with or without hypertension. After multivariable adjustments, this relationship remained rather stable across hypertension status, and no significant hypertension $\times$ RHR interactions were observed, which was consistent with our main findings and previous study. ${ }^{1}$

However, this study had several limitations. First, its retrospective nature reduce the statistical power of this study. Meanwhile, the sample size was relatively small, which limited our ability to assess the short-term prognosis due to the small number of death events. Thus, prospective, large sample size studies are required to validate the results of this study. Second, we could not obtain any medication information that may directly affect the RHR. This may be an important confounder, but we were unable to incorporate into the multivariable models. Third, only admission RHR was included in the analysis, which could not fully reflect the entire period. Finally, although we adjusted for potential confounders, many unknown variables might not have been included in the analyses.

In conclusion, an increase in RHR was independently associated with all-cause mortality, and may be a useful prognostic predictor for elderly patients with hip fracture. 
Table 4 Sensitivity Analysis by Hypertension for I-Year and Total All-Cause Mortality

\begin{tabular}{|l|c|c|c|c|c|c|}
\hline \multirow{2}{*}{} & \multicolumn{3}{|c|}{ I-Year Mortality } & \multicolumn{2}{c|}{ Total Mortality } \\
\cline { 2 - 7 } & HR (95\% Cl) & p value & $\begin{array}{c}\text { Interaction } \\
\text { p value }\end{array}$ & HR (95\% CI) & p value & $\begin{array}{c}\text { Interaction } \\
\text { p value }\end{array}$ \\
\hline $\begin{array}{l}\text { Hypertension } \\
\text { Yes }\end{array}$ & $1.40(1.09-1.79)$ & 0.008 & 0.144 & & 0.875 \\
No & $1.17(1.01-1.35)$ & 0.031 & & $1.30(1.07-1.57)$ & 0.007 & \\
\hline
\end{tabular}

Notes: Adjusted for age, sex, body mass index, hip fracture type, Charlson comorbidity index, treatment modality, lymphopenia, anemia and hypoalbuminemia.

Abbreviations: $\mathrm{HR}$, hazard ratio; $\mathrm{Cl}$, confidence interval.

\section{Data Sharing Statement}

The datasets used and/or analysed during the current study are available form the corresponding author on reasonable request.

\section{Ethics Approval and Consent to Participate}

The study was performed according to the Declaration of Helsinki, and approved by the Institutional Ethics Committee of Deyang People's Hospital. As a retrospective study, the Ethics Committee agreed to waive the requirement for the informed consent, and all patient-related data were anonymized to ensure confidentiality.

\section{Acknowledgments}

We thank several nurses from the Department of Orthopedics in the Deyang People's Hospital, for the help with the data inspection.

\section{Funding}

This study was supported by Deyang Science and Technology Bureau (No. 2019SZ125), and Sichuan Science and Technology Program (No. 2019YFS0443, No. 2018JY0389).

\section{Disclosure}

The authors declare that they have no competing interests.

\section{References}

1. Zhao MX, Zhao Q, Zheng M, et al. Effect of resting heart rate on the risk of all-cause death in Chinese patients with hypertension: analysis of the Kailuan follow-up study. BMJ Open. 2020;10(3):e032699. doi:10.1136/bmjopen-2019-032699

2. Lau K, Malik A, Foroutan F, et al. Resting heart rate as an important predictor of mortality and morbidity in ambulatory patients with heart failure: a systematic review and meta-analysis. J Card Fail. 2021;27 (3):349-363. doi:10.1016/j.cardfail.2020.11.003
3. Alapati V, Tang F, Charlap E, et al. Discharge heart rate after hospitalization for myocardial infarction and long-term mortality in 2 US registries. $J$ Am Heart Assoc. 2019;8(3):e010855. doi:10.1161/ JAHA.118.010855

4. Yang L, Pellikka P, Enriquez-Sarano M, et al. Diastolic blood pressure and heart rate are independently associated with mortality in chronic aortic regurgitation. Am Coll Cardiol. 2020;75(1):29-39. doi:10.1016/j.jacc.2019.10.047

5. Omlor A, Trudzinski F, Alqudrah M, et al. Time-updated resting heart rate predicts mortality in patients with COPD. Clin Res Cardiol. 2020;109(6):776-786. doi:10.1007/s00392-019-01572-1

6. Zafrir B, Azencot M, Dobrecky-Mery I, Lewis B, Flugelman M, Halon D. Resting heart rate and measures of effort-related cardiac autonomic dysfunction predict cardiovascular events in asymptomatic type 2 diabetes. Eur J Prev Cardiol. 2016;23(12):1298-1306. doi: $10.1177 / 2047487315624747$

7. Custodis F, Roggenbuck U, Lehmann N, et al. Resting heart rate is an independent predictor of all-cause mortality in the middle aged general population. Clin Res Cardiol. 2016;105(7):601-612. doi:10.1007/s00392-015-0956-7

8. Li K, Yao C, Yang X, Dong L. Effect of resting heart rate on all-cause mortality and cardiovascular events according to age. J Am Geriatr Soc. 2017;65(5):989-994. doi:10.1111/jgs.14714

9. Chen X, Ma Y, Deng Z, Li Q, Liao J, Zheng Q. Prediction of early postoperative major cardiac events and in-hospital mortality in elderly hip fracture patients: the role of different types of preoperative cardiac abnormalities on echocardiography report. Clin Interv Aging. 2020;15:755-762. doi:10.2147/CIA.S250620

10. Kado D, Lui L, Cummings S. Rapid resting heart rate: a simple and powerful predictor of osteoporotic fractures and mortality in older women. J Am Geriatr Soc. 2002;50(3):455-460. doi:10.1046/j.15325415.2002.50110.x

11. Wang Z, Jiang W, Chen X, Yang L, Wang H, Liu Y. Systemic immune-inflammation index independently predicts poor survival of older adults with hip fracture: a prospective cohort study. $B M C$ Geriatr. 2021;21(1):155. doi:10.1186/s12877-021-02102-3

12. Meyer A, Ek S, Drefahl S, Ahlbom A, Hedström M, Modig K. Trends in hip fracture incidence, recurrence, and survival by education and comorbidity: a Swedish Register-based Study. Epidemiology. 2021;32(3):425-433. doi:10.1097/EDE.0000000000001321

13. Nijman S, Groenhof T, Hoogland J, et al. Real-time imputation of missing predictor values improved the application of prediction models in daily practice. J Clin Epidemiol. 2021;134:22-34. doi:10.1016/ j.jclinepi.2021.01.003

14. Tan J, Beilharz J, Vollmer-Conna U, Cvejic E. Heart rate variability as a marker of healthy ageing. Int J Cardiol. 2019;275:101-103. doi:10.1016/j.ijcard.2018.08.005

15. Hartaigh B, Allore $H$, Trentalange $M$, et al. Elevations in time-varying resting heart rate predict subsequent all-cause mortality in older adults. Eur $J$ Prev Cardiol. 2015;22(4):527-534. doi: $10.2047 / 487313519932$ 
16. Floyd J, Sitlani C, Wiggins K, et al. Variation in resting heart rate over 4 years and the risks of myocardial infarction and death among older adults. Heart. 2015;101(2):132-138. doi:10.1136/heartjnl2014-306046

17. Cha Y, Ha Y, Ryu H, et al. Effect of heart failure on postoperative short and long-term mortality in elderly patients with hip fracture. Injury. 2020;51(3):694-698. doi:10.1016/j.injury.2020.01.004

18. Frenkel A, Zeldetz V, Gat R, et al. Atrial fibrillation and mortality in the oldest old after surgery for hip fractures. Gerontology. 2021;67 (3):299-305. doi:10.1159/000513450

19. Cui X, Mandalenakis Z, Thunström E, Fu M, Svärdsudd K, Hansson $P$. The impact of time-updated resting heart rate on cause-specific mortality in a random middle-aged male population: a lifetime follow-up. Clin Res Cardiol. 2021;110(6):822-830. doi:10.1007/s00392-020-01714-w

20. Guo Q, Xiao Z, Lin M, et al. Heart rate fluctuation predicts mortality in critically ill patients in the intensive care unit: a retrospective cohort study. Ann Transl Med. 2021;9(4):334. doi:10.21037/atm-20-7897

21. Lee K, Kim B, Han M, et al. Effect of heart rate on stroke recurrence and mortality in acute ischemic stroke with atrial fibrillation. Stroke. 2020;51(1):162-169. doi:10.1161/STROKEAHA.119.026847

22. Guo Q, Li H, Ouyang H, et al. Heart rate fluctuation and mortality in critically ill myocardial infarction patients: a Retrospective Cohort Study. Front Cardiovasc Med. 2021;8:577742. doi:10.3389/ fcvm.2021.577742
23. Zhao Q, Li H, Wang A, et al. Cumulative resting heart rate exposure and risk of all-cause mortality: results from the Kailuan Cohort Study. Sci Rep. 2017;7:40212. doi:10.1038/srep40212

24. Dahl Aarvik M, Sandven I, Dondo T, et al. Effect of oral $\beta$-blocker treatment on mortality in contemporary post-myocardial infarction patients: a systematic review and meta-analysis. Eur Heart J Cardiovasc Pharmacother. 2019;5(1):12-20. doi:10.1093/ehjcvp/ pvy034

25. Gilstrap L, Austin A, O'Malley A, et al. Association between beta-blockers and mortality and readmission in older patients with heart failure: an instrumental variable analysis. J Gen Intern Med. 2021;36(8):2361-2369. doi:10.1007/s11606-021-06901-7

26. Stolfo D, Uijl A, Benson L, et al. Association between beta-blocker use and mortality/morbidity in older patients with heart failure with reduced ejection fraction. A propensity score-matched analysis from the Swedish Heart Failure Registry. Eur J Heart F. 2020;22 (1):103-112. doi:10.1002/ejhf.1615

27. Ismail A, Ahl R, Forssten M, et al. The interaction between peradmission $\beta$-blocker therapy, the revised cardiac risk index, and mortality in geriatric hip fracture patients. J Trauma Acute Care Surg. 2021;Publish Ahead of Print. doi:10.1097/ TA.0000000000003358

28. Ahl R, Mohammad Ismail A, Borg T, et al. A nationwide observational cohort study of the relationship between beta-blockade and survival after hip fracture surgery. Eur J Trauma Emerg Surg. 2021. doi:10.1007/s00068-020-01588-7
International Journal of General Medicine

\section{Publish your work in this journal}

The International Journal of General Medicine is an international, peer-reviewed open-access journal that focuses on general and internal medicine, pathogenesis, epidemiology, diagnosis, monitoring and treatment protocols. The journal is characterized by the rapid reporting of reviews, original research and clinical studies

\section{Dovepress}

across all disease areas. The manuscript management system is completely online and includes a very quick and fair peer-review system, which is all easy to use. Visit http://www.dovepress.com/ testimonials.php to read real quotes from published authors. 